\title{
Emerging ecosystem services governance issues in the Belgium ecosystem services community of practice
}

\author{
Hans Keune ${ }^{\mathrm{a}, *}$, Nicolas Dendoncker ${ }^{\mathrm{b}}$, Florin Popa ${ }^{\mathrm{a}}$, Jacobs Sander ${ }^{\mathrm{c}}$, \\ Stephan Kampelmann ${ }^{\mathrm{d}}$, Fanny Boeraeve ${ }^{\mathrm{e}}$, Marc Dufrêne ${ }^{\mathrm{e}}$, Tom Bauler ${ }^{\mathrm{d}}$, Jim Casaer ${ }^{\mathrm{c}}$, \\ Tanya Cerulus ${ }^{\mathrm{f}}$, Geert De Blust ${ }^{\mathrm{c}}$, Bart Denayer ${ }^{\mathrm{g}}$, Lieve Janssens ${ }^{\mathrm{h}}$, Inge Liekens ${ }^{\mathrm{i}}$, \\ Jeroen Panis ${ }^{g}$, Thomas Scheppers ${ }^{c}$, Ilse Simoens ${ }^{c}$, Jan Staes ${ }^{j}$, Francis Turkelboom ${ }^{c}$, \\ Paula Ulenaers ${ }^{\mathrm{k}}$, Katrien Van der Biest ${ }^{\mathrm{j}}$, Jan Verboven ${ }^{\mathrm{k}}$ \\ ${ }^{a}$ Belgian Biodiversity Platform E Research Institute for Nature and Forest (INBO), Kliniekstraat 25, 1070 Brussels, Belgium \\ ${ }^{\mathrm{b}}$ Université de Namur, Belgium \\ ${ }^{\mathrm{c}}$ Research Institute for Nature and Forest (INBO), Belgium \\ ' Université libre de Bruxelles, Belgium \\ e Université de Liège, Belgium \\ ${ }^{\mathrm{f}}$ Regional Landscape Dijleland, Belgium \\ ${ }^{g}$ Agency for Nature and Forest (ANB), Belgium \\ ${ }^{\mathrm{h}}$ Provence of Antwerp, Belgium \\ ${ }^{\mathrm{i}}$ Flemish Institute of Technological Research (VITO), Belgium \\ ${ }^{\mathrm{j}}$ University of Antwerp, Belgium \\ ${ }^{\mathrm{k}}$ Flemish Land Organisation (VLM), Belgium
}

\section{A R T I C L E I N F O}

\section{Article history:}

Received 31 October 2014

Received in revised form

22 March 2015

Accepted 17 June 2015

Available online 15 July 2015

\begin{abstract}
A B S T R A C T
In this paper we will focus on how governance issues are being dealt with in the BElgium Ecosystem Services (BEES) Community of Practice and on some Belgian Ecosystem Services (ES) research projects aimed at policy or practice support. As ES governance is still mainly an aspect of policy or practice oriented research, we will specifically focus on method and methodological decision making. The system or systems we aim to govern are complex. But also the governance processes are inherently complex. How do we take this complexity into account in decision support? Do we acknowledge complexity in our approach or do we drastically simplify and reduce it to relatively simple proportions? The methodological approach of decision support methods is open for debate as neither crystal clear nor undisputed yardsticks for best practices exist. On an ambition level, BEES members generally seem to prefer transdisciplinary as well as inclusive valuation approaches, though not exclusively in all circumstances. In Belgium research projects, similar to the developments within BEES, from a research practice dominated by scientists, gradually research processes are opening up to transdisciplinary collaboration. Simultaneously these processes gradually shift from mainly top down approaches to bottom up approaches or hybrid combinations of both entry points. A closer and more nuanced view shows that real transdisciplinary collaboration in Belgian ES research still is only at the beginning. Partly this can be explained by the fact that inter- and transdisciplinary approaches are perhaps more realistic, but also have to deal with more social complexity. New balances have to be found between sophistication and pragmatics. Also the role of science can become more ambiguous: the closer to stakeholders, the more an independent role can be questioned. Regarding ES valuation methods, in general a trend towards more inclusive valuation is clearly noticeable in Belgian ES research, inclusive in the sense of a diversity of ES valuation aspects to be taken into account, diverse types of expression of value(s), a combination of quantifiable and qualitative information, and a diversity of valuators by way of more bottom-up approaches. Still, there are quite some differences between projects and challenges for integration.
\end{abstract}

(c) 2015 Elsevier B.V. All rights reserved.

\footnotetext{
* Corresponding author.

E-mail address: hans.keune@inbo.be (H. Keune).
}

\section{Introduction}

In this paper we will focus on how governance issues are being dealt with in the BElgium Ecosystem Services (BEES) Community 
of Practice (CoP). We will focus on the CoP and on some Ecosystem Services (ES) related research projects of members of BEES, in which ES policy or practice support is a key feature. As ES governance is still mainly an aspect of policy or practice oriented research, we will specifically focus on method (how to take into account ES in practice?) and the methodological decision making process (who was involved in problem framing, choosing the research approach, developing methods etc.). (1) We will briefly introduce ES governance and highlight developments in policy practice and in science relevant for the discussion of Belgian ES governance. (2) We introduce BEES and focus on governance aspects. (3) We introduce several Belgian ecosystem services research projects of members of this community and focus on methodological decision making. (4) We will draw some conclusions.

\subsection{Ecosystem services governance}

With the introduction of the concept of $E S$, proponents of nature and biodiversity conservation aim to demonstrate the importance of nature and biodiversity for mankind (e.g. Cowling et al. (2008) call it a mission-oriented discipline). As such, the conservation community hopes to convince society of the need and urgency to take action. A dominant strategy for this purpose seems to be one way conviction by means of establishing an evidence base. The question is if this is realistic. In trying to connect this body of evidence and conviction to 'others' and 'their' way of doing things (individual or household or company behaviour, governance in different sectors and at different levels), this largely one-way communicative approach seems to underestimate its limitations: the issue of ES is only partly a knowledge (or scientific or 'truth') issue, it is also an issue of social debate and of governance.

Whereas governing refers mainly to governmental steering and top down management of society, governance refers more to the social process of acting, interacting and decision making. (Lee 2003) refers to it as social coordination: "solving social problems by coordinating interactions of various actors". This means that it is not necessarily limited to formal governmental institutions or the work of policy makers only. It could also refer to corporation management or local communities, or even households. As all of these actors potentially play a role in or are influenced by ecosystem governance, or can be considered actors and/or stakeholders in other societal domains, sectors, activities that (potentially) have some relation to ecosystems and their services, it is clear that we may speak of a potentially rather complex constellation, linking quite some diversity of contexts, actors, interests and relations. Moreover according to Jordan (2008)"governance is not normally tied to a particular period of time or geographical place; it is a concept that travels easily across these categories". Hooghe and Marks (2003) refer to this as multilevel governance (. The challenge of how to institutionally arrange ecosystem governance urges us to pose and try answer quite some important questions such as:

1. What to govern: nature and society; issues, problem framing; policy options, priorities, ...;

2. Who is relevant: stakes, power; benefits, burdens;

3. Who should be involved: which groups, actors, stakeholders;

4. When should actors be involved: e.g. at which phase of the governance process, such as issue/problem framing, research/ process design, research, social/policy interpretation, definition of policy options, prioritization, practical action, evaluation;

5. Where should actors be involved: e.g. which policy level, spatial scale or sector of society;

6. Why should actors be involved: e.g. do we involve local actors because they have a democratic right to be involved or because we need their support for the legitimacy of the governance process, or because we need their local knowledge or because we want to raise their awareness?

7. How should actors be involved: e.g. voluntarily, top down or bottom up, by which rules, how is power distributed;

8. Based on which information: which and whose data or knowledge.

Attention for and development of governance in real-world practice is urgently needed according to several scholars in the dynamic field of ecosystem services (Cowling et al., 2008; Daily et al., 2009; de Groot et al., 2010; Haines-Young, 2011; Fish, 2011). These scholars realize that the 'speaking truth to power' strategy (as coined by Jasanoff (1990)) is an oversimplification of the social complexity of ecosystem governance issues (Lebel et al., 2006). We will now further focus on two governance developments we consider relevant for the discussion about ES governance in Belgium: governance developments in policy practice and in science.

\subsection{Governance in policy practice}

'Governance' encompass a wider, more inclusive and extensive set of perspectives on institutional arrangements than 'governing' or 'government' (Keune et al., 2013d; Voß and Bornemann, 2011; Lee, 2003; Hooghe and Marks, 2003; Kemp et al., 2005; Kitthananan, 2006; Jordan, 2008; Kluvánková-Oravská et al., 2009). Andrew Jordan mobilizes Rosenau (1992) to give an account of the differentiation between both conceptualisations: 'Both [governance and governing/government] refer to purposive behaviour, to goal oriented activities, to systems of rule; but 'government' suggests activities that are backed by formal authority (...) whereas 'governance' refers to activities backed by shared goals that may or may not derive from legal or formally prescribed responsibilities. (...) 'Governance', in other words, is a more encompassing phenomenon than 'government'. It embraces governmental institutions, but it also subsumes informal, non-governmental mechanisms (...) whereby those persons and organizations within its purview move ahead, satisfy their need and fulfil their wants.' In other terms, whereas 'governing' refers quite explicitly to a theory of public intervention that favours public authority-based - aka governmental-steering of societies, 'governance' refers to the soci(et)al processes of acting and interacting in decision making, in implementation and in evaluation of public policy. 'Governance' hence accounts for a less linear, less one-directional, less instrumental, less substantive, less exclusive relationship between public authorities and their subjects.

To unambiguously define governance is a challenge (Keune et al., 2013c): according to Jordan (2008) it is one 'of the most essentially contested terms in the entire social sciences'. But perhaps to define it narrowly would also be a pity: as with other rather vaguely defined 'buzzwords' like 'sustainable development', by defining it too narrowly one runs the risk of excluding, rather than including a diversity of those actors, groups, one would want to involve, to join forces with, one might lose an audience (Hajer, 1995; Jordan, 2008). We perceive governance as an important challenge, open for debate, with options to invent and choose from, with practical relevance for ecosystem services, but without an unambiguous clear definition or roadmap.

From an overview of a diversity of relevant governance approaches and conceptualizations, both ES specific and more general (Keune et al., 2013c), several choice elements and challenges stand out, commonly captured under the notion of complexity. The system or systems we aim to govern are complex. But also the governance processes are inherently complex and therefore difficult to capture or steer in terms of effectiveness. Some key attributes and challenges of governance arrangements follow from the complexity challenge (Keune et al., 2013c). First, taking into account complexity is an important step as such: not only ecological 
complexity, but indeed also social complexity, and best in an integrated manner. This challenge still seems prominent in the field of ecosystem services. Second, a turn from characterizing governance arrangements to assessing their problem-solving potential, or in other words their effectiveness. Thirdly, adaptive management or learning by doing approaches seem to be favoured by most approaches. In order to deal with complexity and also adapt to changes, fourthly balances between several dichotomous traits such as formal-informal, stable-flexible and top-down-bottomup have to be found. Fifthly, it seems that governance regimes that are characterized by more complexity and diversity of the above mentioned traits may have a higher adaptive capacity. Sixthly, context dependency is important to take into account, both when designing, when applying and adapting, and in assessing governance processes. Finally, governance explicitly refers to practice: governance is about doing, is about real life, it is not only about academic discussions. And, importantly, ecosystem governance is open for discussion.

\subsection{Governance in science}

Dealing with complexity means that the knowledge component of governance is crucial: scientific underpinning of policy and practice options. It is a long way though, from scientific knowledge to concrete policy action (Keune and Dendoncker, 2013). Along the way many decisions have to be made. A lot of these decisions relate to setting priorities: given that one can do a lot but not everything, one has to choose. Framing complexity is a crucial aspect of any ecosystem services approach: how do we deal with ecological and social complexity? The complexity to be taken into account and the approach for dealing with that complexity is part of context specific negotiation amongst actors involved in the process of investigation and interpretation, and as such becomes negotiated complexity.

The relation between the natural environment and humans is highly complex and still poorly understood (Liu et al., 2007). In case of ecosystem services the complexity is partly caused by the interdisciplinary nature of the issues (Haines-Young, 2011): both natural and social sciences have to be involved and different subject areas need to be integrated. This interdisciplinary challenge is huge at the level of coupled human and natural systems (Liu et al., 2007), let alone in the young field of ecosystem services. Complexity moreover causes the potential array of policy options to be diverse and difficult to objectify due to uncertainties, ambiguity, ignorance and indeterminacy, which challenges the evidence base for ecosystem services management (Fish, 2011). But the challenge is also trandisciplinary in nature as a new level of complexity (Fish, 2011) comes into play when interpreting knowledge for society, when linking to decision-making processes. We move here from "knowledge about" to deciding "what is important". This not only brings a diversity of societal sectors into play, as ecosystem services relate to different aspects of society and thus to various policy fields. This also brings into play a diversity of interests and stakes.

How does one take this complexity into account in decision support? Does one acknowledge complexity in the approach or does one drastically simplify and reduce it to relatively simple proportions? The methodological approach of decision support methods is open for debate as neither crystal clear nor undisputed yardsticks for best practices exist (Lindblom and Cohen, 1979; Rosenhead, 1989; Weiss, 1991; Marakas, 1999; Belton and Stewart, 2002). The challenge is not only to do justice to the complexity of many decision-making issues and processes, but also to do this as pragmatically as possible.

Already in 1989 Rosenhead sketched the need for an alternative methodological paradigm for dealing with issues that are characterized by "complexity, uncertainty and conflict". Almost simultaneously Funtowicz and Ravetz (1990, 1991, 1994) presented their critique on normal science, pleading for a post-normal paradigm in cases when "facts are uncertain, values in dispute, stakes high and decisions urgent", and do so by referring mainly to environmental issues. Funtowicz and Ravetz build upon the concept of normal science, as coined by Thomas Kuhn (1962), and describe it as puzzle solving within a scientific paradigm that is not disputed as such, clearly stipulating how the scientific endeavor should be performed as to solve problems, or more in general defines the truth. The alternative of post-normal science, especially applicable to complex issues, focuses on aspects of problem solving that are often neglected in traditional normal science: uncertainty and values. Funtowicz and Ravetz plead for a wider involvement/participation of actors next to scientific experts and a more explicit account of scientific uncertainties. Such transdisciplinary or post-normal approaches aim "to integrate the best available knowledge, reconcile values and preferences, as well as create ownership for problems and solution options" (Lang et al., 2012). Early involvement is crucial, as environmental assessments depend heavily on how issues are selected and framed (Briggs, 2008). The process of methodological decision-making thus is crucial for the governance approach it underpins.

\section{The BElgium Ecosystem Services Community of Practice}

We will now introduce the BElgium Ecosystem Services Community of Practice (BEES), which tries to add to ES governance relevant community building by connecting interested parties from a diversity of backgrounds, both from science, policy and stakeholder organizations. As such BEES exemplifies transdisciplinarity from a bottom up perspective, aiming at facilitating science-policy-society interfaces and capacity building.

\subsection{The BElgium Ecosystem Services (BEES): From science cluster to community of practice}

The BElgium Ecosystem Services (BEES) cluster project (20092012; Jacobs et al., 2013) aimed to deliver an overview of ES issues at stake, from environmental, economic to sociological perspectives, to bring together scientists involved in ES research, policy makers and other stakeholders, and to advise on priority research and actions needed to come to an adequate strategy on sustainable management of these vital assets to human well-being. This project, though largely focusing on scientific issues, expanded on the exploration of the need for socially and policy-relevant knowledge. Capitalizing on this project, the BEES Community of Practice (CoP) (BEES: BElgium Ecosystem Services) (http://www.beescommunity.be/) emerged to further engage a variety of Belgian policy and private sector representatives and other stakeholders as to improve the societal relevance of future scientific work through close consultation and collaboration. It further aims to build bridges to other sectors in society, such as the business sector, in order to collaborate in practice-oriented projects.

After a widely distributed open invitation, On April 26th of 2012 during a round table discussion, a group of Belgian actors from science and policy convened and decided to establish a Community of Practice on ES in Belgium. A Community of Practice (Wenger and Snyder, 2000; Meessen et al., 2011) is a network made up of individuals and organizations that share an interest and practice, who come together to address a specific challenge, and further each other's goals and objectives in a specific topic area.

The round table participants agreed upon the following aims of this BEES community:

1. Develop mainstreaming and policy tools, to promote the acquisition of an improved knowledge on the uptake of ES concepts in policy and management, business and society; 
2. Facilitate capacity building, exchange of expertise and experience, to enable involvement of Belgian actors in international initiatives and build the capacity to conduct assessments of ES;

3. Provide overview of state of the art knowledge and best practices.

The BEES community is an open and flexible network that serves as interface between different societal actors. It is open to all organizations, and informal in its functioning, organization and membership, there are no restrictions to community membership. Its activities are demand-driven, responsive to societal needs, and it promotes engagement of Belgian ES experts in relevant national and international initiatives, such as, the Intergovernmental Platform on Biodiversity and Ecosystem Services (IPBES), the EU Working Group on Mapping and Assessment of Ecosystems and their Services (MAES), The Economics of Ecosystems and Biodiversity (TEEB) and the Ecosystem Services Partnership (ESP). The BEES community is supported by a secretariat facilitated by the Belgian Biodiversity Platform (http://www.biodiversity.be/). The Belgian Biodiversity Platform is funded by the Belgian Science Policy office, which also supports BEES for organizing meetings.

\subsection{ES governance viewed by ES actors}

With respect to the policy relevance of ecosystem service science a survey (Keune and Bauler, 2012) was set up as to highlight the views of a diversity of BEES members: scientists, policy representatives and others. The survey touched upon valuation issues, context dependency, the role of biodiversity, the policy relevance of scientific knowledge on ecosystem services, the science-policy interface, scientific objectivity and independence, knowledge communication from science to policy, the responsibility of social scientists and the knowledge ability about science or policy for subsequent 'other actors'. The survey was distributed amongst the BEES community (at that stage mainly ES scientists, and to a lesser extent policy representatives) and the personal mailing lists of the researchers organizing the survey, with the special request for further dissemination to other interested actors via the people addressed by the survey. As such we hoped to get response from Belgian actors interested in the ES concept. We will briefly reflect on some results which address governance relevant issues.

Valuation of ES is both considered as a scientific responsibility and a topic for social and political debate. Some respondents propose a strict division of responsibilities between science and society, whereas others do not make a clear distinction between science and society regarding valuation and point at the need for close collaboration, between scientific disciplines, between science and society, and some do not even make a distinction between science and society at all when it comes to science, e.g. by pointing at the importance of citizen science. Quite some respondents (mainly those in favour of scientific valuation) touch upon the debate about valuation and monetization. As pro-monetization arguments especially the awareness raising capability is mentioned. Opponents of monetary valuation point at context dependency of ecosystem services, therefore monetary value having little significance. Most respondents are in favour of close collaboration between scientists and policy representatives, though some concerns are raised about the independency/neutrality of science from political influence. Most respondents consider scientists to have the responsibility to be objective and independent, e.g. in order to be credible as a scientist. But it is also stated to be mainly an ideal that in reality is not straightforward, or even impossible. The importance of objectivity and independence does not necessarily mean that scientists should mainly focus on issues that can be objectified: $57 \%$ agrees, $32 \%$ disagrees.
Concerning method development and use, different collaborative scenarios appear appealing for the majority of respondents: 1 . science develops best practices to be used by policy or 2 . science and policy collaborate in the use of methods. Respondents are inconclusive about the choice between on the one hand a rather strict division of labour between science and policy and close collaboration on the other: a majority clearly sees benefits from both scenarios, and thus does not necessarily see them as excluding options. Of course both scenarios do not need to be mutually exclusive and can both be incorporated.

In another analysis of the views of a diversity of BEES actors (Keune et al., 2013b), also a clear tension appears between some policy actors' desire to acquire tools for monetary valuation and the risks perceived by others on strictly monetary valuation (e.g. commodification of nature, neglect of other values, etc.). On the one hand, there is the need for 'proof of concept', and the availability of economic tools and mainstream character of 'money talk' is a pragmatic choice. On the other hand, we note a strong need for broader valuation approaches and a critical attitude towards the culture of 'math and money' at all levels: it is perceived as one of the main causes of social and ecological unsustainability. Another tension appears between top-down (science and policy driven) approaches and more bottom-up, participatory approaches. Several actors urge for more collaborative approaches of ES valuation, e.g. to build trust between providers and beneficiaries, as monetary valuation is not relevant in their working context. Among the suggested solutions are the development of alternative, more inclusive governance methods and practices-amongst others using social debate and including relations between humankind and nature-as well as methods to integrate different types of values (e.g. economic, cultural heritage, and biodiversity) in decision making.

Both analyses clearly show appreciation for transdisciplinary collaboration and ambiguity regarding valuation methods: both the benefits and drawbacks of monetization are mentioned, compared to more sophisticated and inclusive valuation approaches (Dendoncker Nicolas et al., 2013).

\subsection{Community of practice governance aspects}

Recently, on both of the above mentioned governance and methodological aspects, transdisciplinarity and valuation/assessment methods, the BEES community produced several ES governance relevant communications. As such, as a CoP, BEES tries to formulate joint recommendations and reflections, addressing ES governance issues and processes. We will first discuss one example oriented at Belgium and second two examples oriented at EU level ES governance.

\subsubsection{ES governance in Belgium}

On the 9th of July 2013, a group of Flemish, Walloon and Federal policy representatives and scientists (called the 9th of July group) joined with the aim of developing a BEES policy brief to raise awareness on the importance of the uptake of the concept of ES in policy and society at large. The policy brief is published in 2014 as BEES-brief and restates the importance and urgency of ES research and practical implementation for different policy domains. Amongst the recommendations we clearly recognize pleas for transdisciplinary collaboration and inclusive valuation:

\section{Acknowledge the existence of multiple values of biodiversity and ecosystem services}

Sound decisions should integrate all types of value, including less quantifiable ones such as intrinsic value, welfare, good life, liberty of choice, etc., and not be limited to (seemingly) obvious and tangible values. 


\section{Adopt a transdisciplinary approach}

Transdisciplinary cooperation and communication is key to efficient implementation and innovation. Stand-alone economic, ecologic or social approaches will not suffice. Scientists, policy representatives and stakeholders need to act together.

One of the governance processes the 9th of July group had in mind as a target area for the BEES brief, was the Walloon policy process. In Wallonia (French speaking part of Belgium), policy uptake of the ES concept lagged behind compared to Flanders (Dutch speaking part of Belgium). End of 2013, some Flemish BEES members (both from science and policy) together with some Walloon colleagues, were invited to the Cabinet of the Walloon Minister for Sustainable affairs, to bring them up to date about ES developments in general, within BEES and in Flanders in particular. This visit (and before contacts between Walloon and Flemish scientists and policy representatives through BEES) helped inspiring the Walloon government to decide on the installation of and financial support for an ES platform of scientists and members of the Walloon administration. This platform will provide the basis for ES quantification and mapping in Wallonia. As such this is a good example of the success of the BEES community of practice, without which to the conviction of Walloon ES experts, this would probably not have been possible.

The BEES brief, while being under construction, brought to the attention a complicated challenge, by which the initiators were taken by surprise. With good intentions, from the start of the development, the brief was called 'policy brief, which is not uncommon for scientific communities addressing policy makers. It was also agreed upon to ask those who contributed to the brief and later others within BEES, for support of the text of the brief, which would supposedly strengthen the message and the urgency for ES policy uptake. Quite some scientists and policy representatives, both Federal, Walloon and Flemish, agreed to have their names mentioned as supporters. Unexpectedly, this caused quite some concern within some policy departments: the mandate of policy representatives to undersign such policy relevant statement was questioned. Formally this should be approved by the politically responsible Ministers. Clearly here the advantages of having an informal network in which exchange of viewpoints and joint vision and knowledge building can blossom, are confronted with the formal limitations of policy representatives to express their viewpoints without formal political backing. Solutions such as adding a disclaimer about the personal and informal status of their support were disqualified, as it could bring the policy representatives in an awkward position and jeopardize their freedom of joining other BEES initiatives. Therefor it was decided to not list any names and change the header of the brief from 'policy brief' to 'BEES brief'. It was also decided that this formal-informal split should be further discussed, in good spirit, as also the policy hierarchies clearly recognized the added value of policy representatives being involved in BEES. This example clearly shows that new forms of governance can exist next to more formal governmental processes, but also that they sometimes can create friction and become incommensurable. A lesson learned is that these kind of issues may arise but need not necessarily lead to an impasse, but may find a way forward in joint learning and collaboration.

\subsubsection{EU ES governance}

An important European Union ES governance initiative is the EU Mapping and Assessment of Ecosystems and their Services in Europe, one of the key actions of the EU Biodiversity Strategy to 2020 (MAES; http://ec.europa.eu/environment/nature/knowledge/ ecosystem_assessment/). The Belgian MAES working group (facilitated within BEES) recently issued a communication to give feedback on the second MAES report on ES indicators (Joachim
Maes et al., 2014). This Reflection of the Belgian MAES working group on the 2nd MAES report clearly is in support of both a transdisciplinary/stakeholder input and inclusive valuation:

How will indicators be selected in a participatory manner as to raise local stakeholder support for their selection, application and outcomes?

Why is the report focused at physically quantifiable aspects? And moreover, exclusively at data available in a spatially explicit way? How can the many robust quantitative indicators on ES supply, demand and use for which the spatial aspect is absent or unreliable be applied? How can the non-physical indicators be applied?

Another BEES communication recently developed in close collaboration with members of the Dutch Community of Practice Ecosystem Services, also provided feedback on the EU MAES process. Formulated differently and to some extent more firmly, similar feedback on the importance of transdisciplinarity and inclusive valuation was expressed:

To do the assessment and to develop, use and improve the maps interactively, i.e. together with end-users and other stakeholders. This will increase transparency and legitimacy;

To take into account different ways of valuation (including nonmonetary) and different approaches by different stakeholders, without translating them into only one (monetary) unit;

The importance of community of practice contributions apparently is appreciated in the second MAES report (Joachim Maes et al., 2014):

There is a need for capacity-building in all Member States in order to create a community of practice in Europe that will contribute to improve the knowledge and evidence for EU environment policy in line with Priority Objective 5 of the General Union Environment Action Programme to 2020 'living well, within the limits of our planet'.

Whether this EU perspective on CoPs will be in line the preferences highlighted in the BEES communications, remains to be seen, as the MAES process only just started. Here also we may draw the conclusion that new modes of governance like the CoP's may be appreciated even when the spirit of the dominant mode of governance is still aimed mainly at a top-down governmental mode of operation. Openness to new modes of governance will not immediately or necessarily result in widespread change. But it is clear that also within the EU new modes of governance are within the visor, and gain interest.

\section{Methodological decision making in Belgian ES research}

\subsection{Brief introduction of some Belgian ES research projects}

We will now focus on some Belgian ES research projects. The selection of projects was based on a bottom-up interest of Belgian ES projects in joining for a joint publication. This collection of projects covers most relevant ES research projects at that time as well as the larger part of the diversity of the BEES community members. As such the selection displays the variety of ES projects in Belgium quite well. We analysed the projects by studying the descriptions of the projects as were included by the projects. We also send round some questions on valuation approaches and transdisciplinarity. The project descriptions as included in the analysis and this paper and outcomes of the analysis were conveyed to the projects so that they could comment on them if considered necessary. 
We cannot extensively introduce the research projects that form basis for our analysis of methodological decision making. The topical focus amongst the different projects/cases is quite diverse, but can be grouped in two clusters. Four ES projects are specifically aimed at valuation: freshwater ES valuation, regional ES assessment and valuation tools, integrated ES valuation in municipalities and an ES valuation tool. And four ES projects are specifically aimed at a participatory bottom up approach: two participatory regional ES master plans, participatory wild boar management and a bottom-up city soil depollution project. For an overview, see Table 1

All projects to some extent aim to provide policy/socially relevant knowledge, processes and/or solutions. Hence, the ambition to be governance relevant clearly is present. We will now discuss to what extent the projects have a transdsciplinary and inclusive valuation ambition.

\subsection{Methodological decision making process: From expert affair to transdisciplinary coalitions}

Based on a quick scan of the above mentioned research projects, we should distinguish between transdisciplinary collaboration and participation. Participation does not necessarily equal transdisciplinary collaboration: participation can be limited to datainput, e.g. in valuation exercises. Transdisciplinary collaboration refers to joint/collaborative research, potentially including joint methodological design, development and application, research, interpretation and evaluation. Following from this, we should also distinguish parts of the research process were non-scientists feed into the process. Furthermore we should distinguish between different types of non-scientists involved in the research projects. In the ES projects generally three main groups are distinguished: policy representatives, stakeholders and citizens. Finally we should distinguish forms of interaction, between the scientists and non-scientists. Interaction can be rather limited, e.g. through questionnaires, more interactive e.g. through interviews, steering group meetings or end-user meetings, or very interactive by means of research collaboration.

Clearly, similar to the developments within BEES, from a research practice dominated by scientists, gradually research processes are opening up to transdisciplinary collaboration. Simultaneously these processes gradually shift from mainly top down approaches to bottom up approaches or hybrid combinations of both entry points. Several projects still have a strong scientific orientation: scientists are the main methodological decision makers and research actors. It mainly concerns interdisciplinary teams, involving ecological, economic and/or social scientists in different combinations performing this coordination. In other projects though, transdisciplinary collaboration is the starting point, mainly involving policy representatives as non-scientific methodological decision makers and co-researchers, from start to finish. In the less ambitious projects from a transdisciplinarity perspective, still some involvement from non-scientific actors is present, be it more distant, less interactive or intense and with less influence on methodological decision making. Some projects without a clear transdisciplinary collaborative approach, in hindsight conclude the importance of stakeholder involvement for future research, also concerning methodological issues. Main advantages being real-life contexts fitness of tools, products and applications, incorporation of social debate, inclusion of other forms of knowledge, social learning, networking and capacity building, trustworthy relationships and support for the research approach.

We also looked at the funding source (Table 2) for the different projects, assessing whether this could have an influence on stakeholder involvement. All projects have governmental funding, 
Table 2

Project funding sources.

\begin{tabular}{ll}
\hline Project & Funding source \\
\hline ECOFRESH & Federal science policy \\
ECOPLAN & Flemish science policy \\
Nature Value Explorer & Flemish environmental policy \\
VOTES & Federal science policy \\
Inland dunes project & Flemish province \& EU funding \\
Operation Sunflower & National lottery \& Brussels environmental policy \\
De Wijers & Flemish governmental land agency \\
Wild boar management & Flemish governmental nature agency \\
\hline
\end{tabular}

and only one has (also) non-governmental funding. It seems that projects funded by science policy have a tendency to be less focussed on transdisciplinary approaches. An obvious explanation is that the funding agencies are less active in the ES practices which are under investigation in ES research. In most cases often these practice agencies are even actively involved in the case studies, which is not the case for science policy agencies.

\subsection{Method choice: From monetization to inclusive valuation}

Methodologically the projects differ significantly, also from a valuation point of view: what is the meaning of ES, what is the importance of ES and how is it valued? From a governance perspective the questions why do we value, how to value, who values, whose values are important and what is the information basis for valuation, are crucial. Decisions on these valuation relevant issues have an impact on outputs of the valuation research and uptake/ use in practice (Bauler and Pipart, 2013; Dendoncker Nicolas et al., 2013). Several projects acknowledge the importance of economic valuation (in the sense of monetization) for governance, which is currently the dominant focus in international ES research and practice. The rationale behind this is that 'money talks'. This interpretation of governance relevance originally was the main focus for one project (Nature Value Explorer), and of significant importance to the ECOFRESH project. Within the Votes and ECOPLAN projects, monetary valuation is less a central issue: they include also ecological and social valuation perspectives. Three projects largely left it open at the start, leaving it to the actors involved in the process: the Wijers project, the wild boar project and the Inland dunes project. Later on in these projects inclusive approaches were chosen. The Operation Sunflower project does not specifically focus on valuation and is mainly action oriented.

In general a trend towards more inclusive valuation is clearly noticeable in Belgian ES research, inclusive in the sense of a diversity of ES valuation aspects to be taken into account, diverse types of expression of value(s), a combination of quantifiable and qualitative information, and a diversity of valuators by way of more bottom-up approaches. Still, there are quite some differences between projects and challenges for integration ahead.

\section{Conclusions}

The shift from a mainly scientific focus to a more policy relevance focus gradually evolves in most of the Belgian ES research projects presented here. Still we have to conclude that the focus within quite some projects largely is on scientific challenges and only to a lesser extent geared to policy relevance, especially when it comes to transdisciplinarity. The growing BEES-community and its transdisciplinary nature shows that there is a large potential also for research projects to open up to transdisciplinary approaches, including non-scientists in methodological decision making, incorporating diversity of opinions and concerns. It will be key to connect to new developments in both science and governance in order to enhance societal and policy relevance of Belgian ES research.

On an ambition level, BEES members generally seem to prefer transdisciplinary as well as inclusive valuation approaches, though not exclusively in all circumstances. In Belgium research projects, similar to the developments within BEES, from a research practice dominated by scientists, gradually research processes are opening up to transdisciplinary collaboration. Simultaneously these processes gradually shift from mainly top down approaches to bottom up approaches or hybrid combinations of both entry points. A closer and more nuanced view shows that real transdisciplinary collaboration in Belgian ES research still is only at the beginning. Partly this can be explained by the fact that inter- and transdisciplinary approaches are perhaps more realistic, but also have to deal with more social complexity. New balances have to be found between sophistication and pragmatics. Also the role of science can become more ambiguous: the closer to stakeholders, the more an independent role can be questioned. Regarding ES valuation methods, in general a trend towards more inclusive valuation is clearly noticeable in Belgian ES research, inclusive in the sense of a diversity of ES valuation aspects to be taken into account, diverse types of expression of value(s), a combination of quantifiable and qualitative information, and a diversity of valuators by way of more bottom-up approaches. Still, there are quite some differences between projects and challenges for integration.

Whatever governance strategy is chosen, limitations and imperfections are inherent. Moreover it is important to realize that indeed one chooses a governance approach, often being the outcome of negotiation amongst the most prominent actors involved. There are different options for framing socio-ecosystem research and governance and the way crucial how-to-do-governance questions are operationalized is open for context dependent discussion. We may conclude here that the consciousness, explicit planning and evaluation of governance aspects throughout ES projects can make these choices more explicit and transparent. We believe this remains an important challenge within the Belgian ES science and practice context.

\section{References}

Bauler, T., Pipart, N., 2013. Ecosystem Services in Belgian environmental policymaking: expectations and challenges linked to the conceptualisation and valuation of ES. In: Jacobs, S., Dendoncker, N., Keune, H. (Eds.), Ecosystem Services: Global Issues. Local Practices.. Elsevier, New York

BEES: BElgium Ecosystem Services. 〈http://www.beescommunity.be/〉.

Belton, V., Stewart, T., 2002. Muliple Criteria Decision Analysis: An Integrated Approach. Kluwer Academic, Dordrecht.

Briggs, D., 2008. A framework for integrated environmental health impact assessment of systemic risks. Environ. Health 7, 61. http://dx.doi.org/10.1186/ 1476-069X-7-61.

Cowling, R.M., Egoh, B., Knight, A.T., O’Farrell, P.J., Reyers, B., Rouget, M., Roux, D.J., Welz, A., Wilhelm-Rechman, A., 2008. An operational model for mainstreaming ecosystem services for implementation. In: PNAS-July 15, 2008-vol. 105 (28), pp. 9483-9488.

Daily, G.C., Polasky, S., Goldstein, J., Kareiva, P.M., Mooney, H.A., Pejchar, L., Ricketts, T.H., Salzman, J., Shallenberger, R., 2009. Ecosystem services in decision making: time to deliver. Front. Ecol. Environ. 7 (1), 21-28.

de Groot, RS., Alkemade, R, Braat, L, Hein, L, Willemen, L., 2010. Challenges in integrating the concept of ecosystem services and values in landscape planning, management and decision making. Ecol. Complex. 7 (2010), 260-272.

Dendoncker Nicolas, Keune, Hans, Jacobs, Sander, G.ómez-Baggethun Erik, 2013. Inclusive ecosystem services valuation-ecosystem services. In: Jacobs, S. Dendoncker, N., Keune, H. (Eds.), Ecosystem Services - Global Issues Local Practices. Elsevier, New York, pp. 3-12.

Fish, R., 2011. Environmental decision making and an Ecosystems approach: some challenges from the perspective of social science. Prog. Phys. Geogr. 35 (5), 671-680.

Fontaine, C. et al., 2013. Valuation of Terrestrial Ecosystem Services in a Multifunctional Peri-urban Space (VOTES: final report). Federal Science Policy, 
Brussels.

Funtowicz, S.O., Ravetz, J.R., 1990. Uncertainty and Quality in Science for Policy. Kluwer Academic, Dordrecht.

Funtowicz, S.O., Ravetz, J.R., 1991. A New Scientific Methodology for Global Environmental Issues. In: Costanza, R. (Ed.), Ecological Economics: The Science and Management of Sustainability., 1991. Columbia University Press, New York, pp. 137-152.

Funtowicz, S.O., Ravetz, J.R., 1994. The worth of a songbird: ecological economics as a post-normal science. Ecol. Econ. 10-3, 197-207.

Haines-Young, R., 2011. Exploring ecosystem services issues across diverse knowledge domain using Bayesian Belief Networks. Prog. Phys. Geogr. 35 (5), $685-704$.

Hajer, M., 1995. The Politics of Environmental Discourse. Oxford University Press, Oxford.

Hooghe, L., Marks, G., 2003. Unravelling the central state, but how? Types of multilevel governance. Am. Polit. Sci. Rev. 97, 233-234.

Jacobs, S., et al. 2013. Belgium's ecosystem services: a vision for society-nature interactions: BEES. 〈http://www.belspo.be/belspo/ssd/science/Reports/FinalRe port_BEES\%20ML.pdf).

Janssens, L., 2013. Integrating the concept of ecosystem services in the Province of Antwerp: the Inland Dunes project. In: Jacobs, S., Dendoncker, N., Keune, H. (Eds.), Ecosystem Services - Global Issues Local Practices. Elsevier, New York, pp. 393-396 (2013).

Jasanoff, S., 1990. The Fifth Branch. Science Advisers as Policymakers. Harvard University Press, Cambridge, MA.

Joachim Maeset al., 2014. Mapping and Assessment of Ecosystems and their Services-Indicators for Ecosystem Assessments Under Action 5 of the EU Biodiversity Strategy to 2020. 〈http://ec.europa.eu/environment/nature/knowledge/ ecosystem_assessment/pdf/2ndMAESWorkingPaper.pdf).

Jordan, A., 2008. The governance of sustainable development: taking stock and looking forwards. Environ. Plan. C 26 (1), 17-33.

Kemp, R., Parto, S., Gibson, R.B., 2005. Governance for sustainable development: moving from theory to practice. Int. J. Sustain. Dev. 8 (1-2), 12-30.

Keune, H., et al., 2013a. The governance potential of ecosystem services research in Belgium. In: Paper 1st Interdisciplinary Symposium on Sustainable Development. Which transition for Our Societies? Conference Theme: The Role of Public Authorities in the Transition 31st January and 1st February 2013, Namur, Belgium, pp. 73-87. 〈http://www.beescommunity.be/en/publications/〉.

Keune, H., Nicolas, Dendoncker, Sander, Jacobs, 2013b. Ecosystem service practices. In: Jacobs, S., Dendoncker, N., Keune, H. (Eds.), Ecosystem Services - Global Issues Local Practices. Elsevier, New York, pp. 307-315.

Keune, H., Tom, Bauler, Heidi, Wittmer, 2013c. Ecosystem services governance: managing complexity?. In: Jacobs, S., Dendoncker, N., Keune, H. (Eds.), Ecosystem Services - Global Issues Local Practices. Elsevier, New York, pp. 135-155.

Keune, H., Tom, Bauler, Heidi, Wittmer, 2013d. Inquiring into the governance of ecosystem services: an introduction-ecosystem services. In: Jacobs, S., Dendoncker, N., Keune, H. (Eds.), Ecosystem Services - Global Issues Local Practices. Elsevier, New York, pp. 63-69.

Keune, Hans, Bauler, Tom, 2012. What do you Think About the Policy Relevance of Ecosystem Service Science? Results of a Survey Amongst the Belgian Ecosystem Services Expert Community. Instituut voor Natuur-en Bosonderzoek, Brussel, 100 pp. 〈http://www.inbo.be/files/bibliotheek/83/233583.pdf〉.

Keune, Hans, Dendoncker, Nicolas, 2013. Negotiated complexity in ecosystem services science and policy making. In: Jacobs, S., Dendoncker, N., Keune, H. (Eds.), Ecosystem Services - Global Issues Local Practices. Elsevier, New York, pp. $167-180$.

Kitthananan, A., 2006. Conceptualizing governance: a review. J. Soc. Soc. Policy 5 (3), 1-19.

Kluvánková-Oravská, T., Chobotová, V., Banaszak, I., Slavikova, L., Trifunovova, S., 2009. From government to governance for biodiversity: the perspective of central and Eastern European Transition countries. Env. Pol. Gov 19, 186-196.

Kuhn, T., 1962. The Structure of Scientific Revolutions. University of Chicago Press, Chicago.

Lang, D., et al., 2012. Transdiciplinary research in sustainability science: practice, principles, and challenges. Sustain. Sci., 1-17.

Lebel, L., Anderies, J.M., Campbell, B., Folke, C., Hatfield-Dodds, S., Hughes, T.P., Wilson, J., 2006. Governance and the capacity to manage resilience in regional social-ecological systems. Marine Sciences Faculty Scholarship, 52.

Lee M. (2003), Conceptualizing the New Governance: A New Institution of Social Coordination, Paper presented at the Institutional Analysis and Development Mini-Conference, May 3rd and 5th, 2003, Workshop in Political Theory and Policy Analysis, Indiana University, Bloomington, Indiana, USA.

Liekens, I., et al., 2013. The ecosystem services valuation tool and its future developments. In: Jacobs, S., Dendoncker, N., Keune, H. (Eds.), (2013), Ecosystem Services - Global Issues Local Practices. Elsevier, New York, pp. 249-262.

Lindblom, C.E., Cohen, D.K., 1979. Usable Knowledge: Social Science and Social Problem Solving. Yale University Press, New Haven; CT.

Liu, J., Dietz, T., Carpenter, S.R., Folke, C., Alberti, M., Redman, C.L., et al., 2007. Complexity of coupled human and natural systems. Science 317 (5844), 1513-1516.

Marakas, G.M., 1999. Decision Support Systems in the 21st Century, New Jersey. Prentice Hall Pearson Education, USA.

Meessen, B., Kouanda, S., Musango, L., Richard, F., Ridde, V., Soucat, A., 2011. Communities of practice: the missing link for knowledge management on implementation issues in low-income countries? Trop. Med. Int. Health 16 (8), 1007-1014. http://dx.doi.org/10.1111/j.1365-3156.2011.02794.x, august 2011.

Rosenau, J., 1992. Governance, order and change in world politics. In: Rosenau, J., Czempiel, E.O. (Eds.), Governance without Government. Cambridge University Press, UK.

Rational Analysis For A Problematic World. Problem Structuring Methods For Complexity, Uncertainty And Conflict. In: Rosenhead, J. (Ed.), 1989. John Wiley \& Sons, West Sussex, England.

Van Der Biest, K., et al., 2013. Ecosystem services of freshwater ecosystems - "ECOFRESH”. 〈http://www.belspo.be/belspo/ssd/science/Reports/ECOFRESH FinRep_2012_AD_2.pdf .

Verboven, J., Ulenaers, P., 2013. , Integrating ecosystem services in rural development projects in Flanders. In: Jacobs, S., Dendoncker, N., Keune, H. (Eds.) Ecosystem Services - Global Issues Local Practices. Elsevier, New York, pp. 367-372.

Voß J., and Bornemann B. (2011), The politics of reflexive governance: challenges for designing adaptive management and transition management. In: Ecology and Society 16(2):9.

Weiss, C.H., 1991. Policy research: data, ideas, or arguments? In: Wagner, P., Weiss, C.H., Wittrock, B., Wollmann, H. (Eds.), Social Sciences and Modern States: National Experiments and Theoretical Crossroads. Cambridge UP, Cambridge, pp. 307-332.

Wenger, E., Snyder, W.M., 2000. Communities of practice: the organizational frontier. Harvard Bus. Rev. January-February, 139-145. 